\title{
Factors Affecting the Migration and Sequestration of Rumen Protozoa in the Family Isotrichidae
}

\author{
By BURK A. DEHORITY* AND PATRICIA A. TIRABASSO \\ Department of Animal Science, Ohio Agricultural Research and Development Center, \\ The Ohio State University, Wooster, Ohio, USA
}

(Received 5 July 1988; revised 27 October 1988; accepted 14 November 1988)

\begin{abstract}
A chemotactic migration of Isotrichidae, primarily Isotricha and Dasytricha, into sheep rumen contents was observed at feeding time, followed by an abrupt decrease in relative numbers, presumably as a result of sequestration. An increase in the numbers of isotrichids was also observed before feeding, and was not a response to handling or sampling of the animals. When feeding was delayed for $4.5 \mathrm{~h}$, isotrichid numbers increased markedly, falling again when feed was provided. The size of the decrease in numbers after feeding was directly related to feed intake. In general, chemotactic migration of the Isotrichidae was observed $12 \mathrm{~h}$ after feeding, while migration without feeding occurred after 22-24 h. In animals normally fed once daily, the relative number of isotrichids in the rumen contents of an unfed animal about $3 \mathrm{~h}$ after the regular feeding time is probably the best estimate of total isotrichid numbers. Two migrations of the same isotrichids appeared to occur in animals fed twice a day. It is proposed that feeding level controls the amount of storage polysaccharide in the protozoan cell, which in turn controls migration of Isotrichidae into the rumen. The isotrichids appeared to sequester by settling in the ventral rumen.
\end{abstract}

\section{INTRODUCTION}

A diurnal cycle for Dasytricha was first observed in sheep by Purser (1961), who noted a rapid increase in their relative numbers in rumen fluid between 20 and $24 \mathrm{~h}$ after feeding. Warner (1966) observed a similar cycle in sheep for both Dasytricha and Isotricha. This cycle for Isotrichidae differs markedly from that exhibited by the entodiniomorphs, whose numbers decrease at feeding and begin to rise about $8 \mathrm{~h}$ later (Purser \& Moir, 1959; Warner, 1966). The initial decrease in relative numbers of entodiniomorphs is presumably caused by physical dilution factors such as feed and water intake and salivation. The subsequent increase in the population results from protozoal growth in response to nutrients.

Warner (1966) suggested that the Isotrichidae undergo rapid multiplication within a $4-8 \mathrm{~h}$ period around feeding, and then do not divide for about $18 \mathrm{~h}$. However, the numbers of dividing cells observed during the time of rapid increases in Isotrichidae in sheep (Warner, 1966), cattle (Dehority \& Mattos, 1978) and water-buffalo (Michalowski, 1977) do not substantiate this explanation. Clarke (1965) found that numbers of Isotrichidae in cattle did not begin to increase until feeding time, peaking at $2 \mathrm{~h}$ postfeeding and then decreasing rapidly. Additional studies in cattle (Abe et al., 1981; Murphy et al., 1985) substantiated the observations of Clarke (1965), i.e. numbers did not begin to increase until feeding. However, other studies in sheep (Dehority, 1970), water-buffalo (Michalowski, 1975) and goats (Abe et al., 1981) all reported an increase in the numbers of all Isotrichidae prior to feeding.

Abe et al. (1981) observed a thick protozoal mass on the wall of the reticulum of steers slaughtered after overnight starvation. When viewed under the microscope, the mass was found to consist primarily of Isotrichidae protozoa. Based on volume estimates, the mass consisted of about $95 \%$ Isotricha. They proposed that the Isotrichidae sequester on the reticulum wall after 
feeding and then migrate back into the rumen contents when the animal is fed. Possible mechanisms for migration of the Isotrichidae could be a response to a chemical stimulus (chemotaxis), quantity of feed, the act of ingesting feed, contraction of the reticulum at feeding or some combination of all of these.

Since Orpin \& Letcher (1978) were able to show chemotaxis of Isotricha to sucrose, glucose and fructose, it appears highly probable that the Isotrichidae migrate in response to soluble sugars in the incoming feed. Infusion of 3 litres of distilled water, artificial saliva, $0.45 \mathrm{M}-\mathrm{NaCl}$ or a corn starch slurry into the reticulum of two steers at normal feeding time had little if any effect on numbers of Isotrichidae (Murphy et al., 1985). However, a fivefold increase of Isotrichidae was noted in the rumen contents when $0.76 \mathrm{M}$-glucose was infused (this amount of glucose was calculated to equal the soluble carbohydrate content of the ration). The present study was undertaken to study those factors which might control the migration of Isotrichidae into the rumen contents, particularly the migration which seems to occur just before feeding.

\section{METHODS}

Animals and diet. Six rumen-fistulated sheep, 1-2 years old and ranging in weight from $37 \cdot 7$ to $45 \cdot 5 \mathrm{~kg}$, were used in these experiments. Several months before the start of this study, all sheep were inoculated one or more times with sheep rumen contents which contained fairly high numbers of Isotrichidae $\left(1-6 \times 10^{4} \mathrm{ml}^{-1}\right)$. Unless stated otherwise, the animals were fed $800 \mathrm{~g}$ daily of a complete pelleted ration containing $45 \%$ corn cobs, $35 \%$ alfalfa meal, $13 \cdot 1 \%$ oats, $5 \%$ molasses, $0 \cdot 4 \%$ urea and $1.5 \%$ mineral-vitamin supplement. Composite samples of contents from various locations within the rumen were collected through the fistula with the aid of a rigid plastic tube (inside diameter $1.5 \mathrm{~cm}$ ). When sampling time coincided with feeding time, rumen contents were removed and the animals were fed immediately.

In experiments where rumen contents were removed, a 'Shop-Vac' commercial wet vacuum cleaner was used to take out as much of the contents as possible. Some of the residual contents could then be removed by hand with the rigid plastic sampling tube. The volume of contents removed was replaced with an equal volume of warm anaerobic dilution solution (Bryant \& Burkey, 1953).

Where reported, statistical significance was determined with the paired $t$-test. Subsampling, fixation and counting procedures have all been previously described (Dehority, 1984).

Terminology. Before 1980, rumen ciliates were classified in two subclasses, Holotricha and Spirotricha (Honigberg et al., 1964). The genera Buetschlia, Isotricha, Dasytricha and Charonina were all included in the subclass Holotricha and commonly referred to in the literature as holotrichs. Based on taxonomic data obtained by electron microscopy, a revised classification of the protozoa was published in 1980 (Levine et al., 1980). The subclass Holotricha became obsolete, with the genus Buetschlia now classified under the subclass Gymnostomatia and the three remaining genera under the subclass Vestibuliferia. Charonina is classified in the family Blepharocorythidae, while Isotricha and Dasytricha are both classified in the family Isotrichidae. The term isotrichid is used as an abbreviation in this study to denote protozoa in the last two genera.

\section{RESULTS}

\section{Effects of handling, feeding time and sampling}

For the first experiment, all six sheep were adapted to handling for $15 \mathrm{~d}$. The normal routine consisted of the following steps: $(a)$ enter pen at $0800 \mathrm{~h}$ with sampling tube, move sheep into sampling position and simulate removal of rumen fluid, leave barn; (b) return to barn at $0850 \mathrm{~h}$, empty feed bunks and weigh-out feed; $(c)$ feed sheep at $0900 \mathrm{~h}$. Fig. 1 presents the results of a typical experiment with four sheep showing the variation observed in numbers of Isotrichidae around feeding time. For sheep 3 and 4, isotrichid numbers increased prior to feeding, while numbers increased after feeding in sheep 4 and 6. In a replicate experiment (data not shown) all of the sheep were observed to show increases before feeding, after feeding or both. Presumably this increase in number results from migration of the isotrichids into the rumen contents.

In the next set of experiments, feeding was delayed for $4.5 \mathrm{~h}$. The sheep were all handled as described for the previous experiment. Fig. 2 presents the results from one of these experiments and shows that numbers of Isotrichidae began to increase in sheep 3, 4 and 6 just before the normal feeding time and continued to increase for $3-4.5 \mathrm{~h}$. When feed was offered, numbers 


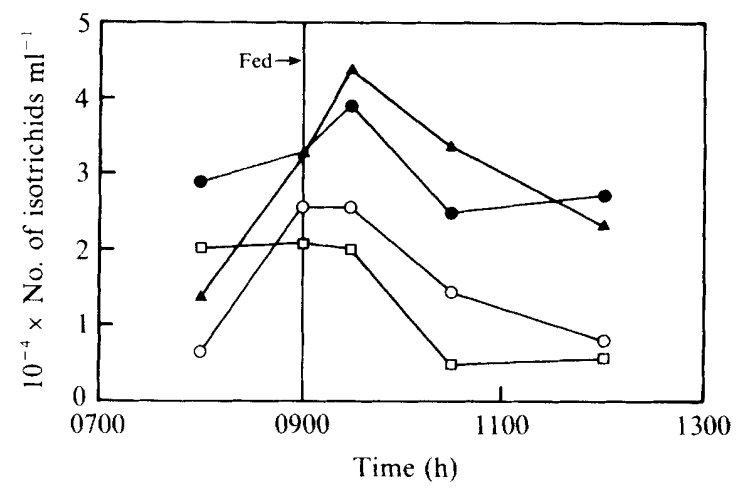

Fig. 1. Changes in numbers of isotrichids in relation to feeding time. The sheep were adapted to a standard procedure for handling, sampling and feeding (see text). $\bigcirc$, Sheep $3 ; \boldsymbol{\Delta}$, sheep $4 ; \square$, sheep 5 ; , sheep 6.

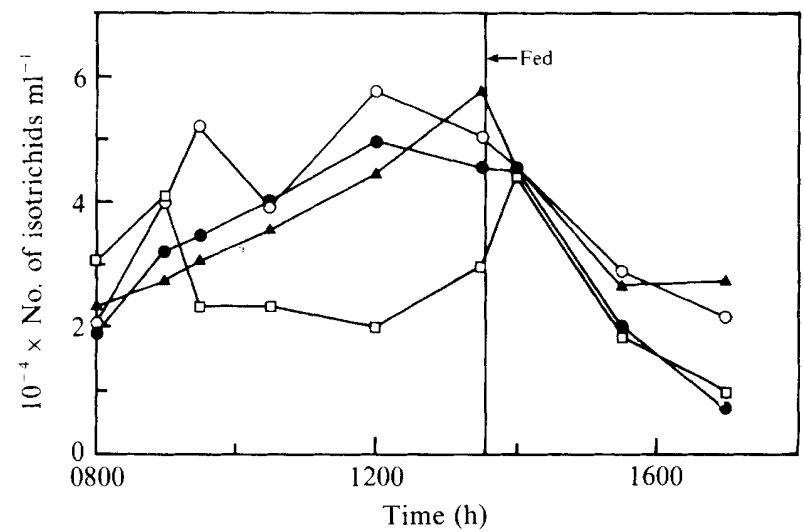

Fig. 2. Effect of delayed feeding on numbers of isotrichids. $\bigcirc$, Sheep $3 ; \boldsymbol{\Delta}$, sheep $4 ; \square$, sheep 5 ; sheep 6. Normal feeding time was $0900 \mathrm{~h}$.

dropped immediately, with no apparent chemotaxis to incoming feed. It is assumed that this decrease in numbers is the result of sequestration of the isotrichids, either on the walls of the reticulum (Abe et al., 1981) or some other as yet unknown site in the rumen. When the numbers of isotrichids did not continue to increase after feed was withheld, as in sheep 5, a chemotactic response to feeding was observed. This experiment was repeated in all four sheep on two additional days, with similar results. If the handler did not enter the barn until $3.5 \mathrm{~h}$ after the normal feeding time $(1230 \mathrm{~h})$ and fed at $4.5 \mathrm{~h}$, similar cycles were observed, i.e. isotrichid numbers were high at $3.5 \mathrm{~h}$ and decreased rapidly after feeding. Thus the isotrichids apparently migrated into the rumen without any known outside stimulus.

Fig. 3 presents the results of a series of experiments with sheep 4, where the animal was first sampled 3, 2 or $1 \mathrm{~h}$ before feeding. Results of the previous studies were substantiated, in that personnel entering the barn and sampling the animal at various times before feeding did not appear to affect isotrichid numbers. Increases were noted before feeding, after feeding or both, and the increase before feeding occurred even when the animal was not sampled previously. A marked increase in isotrichid numbers occurred when sheep 4 was sampled and fed $3 \mathrm{~h}$ before the normal feeding time (Fig. 3). Similar data were obtained for these experiments using three other sheep.

Further studies were done with four of the sheep, on the possible influence of personnel entering the barn and handling the animals before feeding. Essentially there were three 


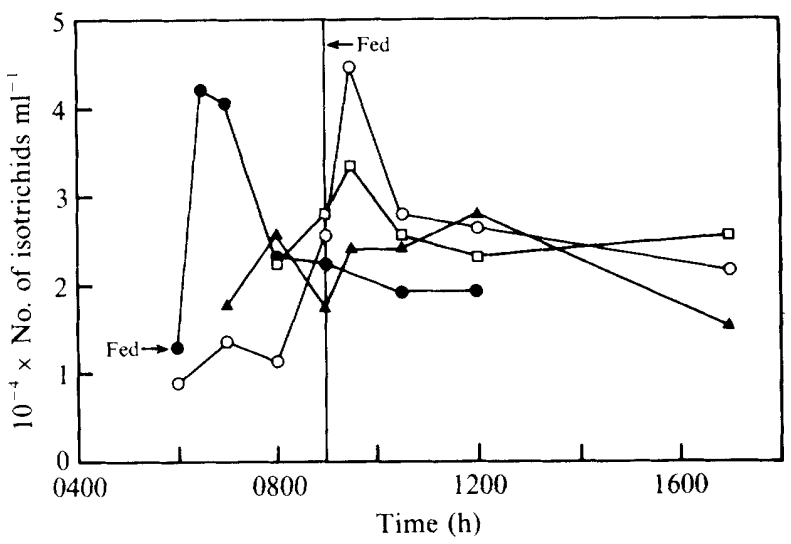

Fig. 3. Effect of initial sampling time and early feeding on numbers of isotrichids in sheep 4. $\bigcirc$, Sampled 3, 2 and $1 \mathrm{~h}$ before feeding; $\boldsymbol{\Lambda}$, sampled 2 and $1 \mathrm{~h}$ before feeding; $\square$, sampled $1 \mathrm{~h}$ before feeding; fed $3 \mathrm{~h}$ before normal feeding time. Normal feeding time was $0900 \mathrm{~h}$.

Table 1. Effect of prior sampling on numbers of isotrichids

\begin{tabular}{|c|c|c|c|c|c|c|c|c|c|}
\hline \multirow{2}{*}{\multicolumn{2}{|c|}{$\begin{array}{l}\text { Sheep no. . . } \\
\text { Sampling time (h) }\end{array}$}} & \multicolumn{8}{|c|}{$10^{-4} \times$ No. of isotrichids $\mathrm{ml}^{-1}$} \\
\hline & & \multicolumn{2}{|c|}{2} & \multicolumn{2}{|c|}{3} & \multicolumn{2}{|c|}{4} & \multicolumn{2}{|c|}{6} \\
\hline $\begin{array}{c}\text { Samp } \\
\text { Experiment } \\
\text { no. }\end{array}$ & $\begin{array}{l}\text { time }(\mathrm{h}) \ldots \\
\text { Feeding } \\
\text { time }(\mathrm{h})\end{array}$ & 0700 & 0900 & 0700 & 0900 & 0700 & 0900 & 0700 & 0900 \\
\hline I & 0900 & $3.02^{a}$ & $6 \cdot 18^{*}$ & $2 \cdot 12$ & $2 \cdot 53$ & $1 \cdot 44^{a}$ & $2 \cdot 37^{*}$ & $1 \cdot 02^{a}$ & $2 \cdot 11^{*}$ \\
\hline II & 0700 & $5 \cdot 23^{b}$ & & $2 \cdot 28$ & & $2 \cdot 48^{b}$ & & $2 \cdot 91^{b}$ & \\
\hline III & 0900 & $3 \cdot 38^{a, b}$ & $5 \cdot 18^{*}$ & $1 \cdot 52$ & 1.98 & $2 \cdot 14^{b}$ & 1.98 & $1 \cdot 76^{a . b}$ & $2 \cdot 94^{*}$ \\
\hline
\end{tabular}

* For each animal, means in the same row are significantly higher $(P<0.05)$ at $0900 \mathrm{~h}$.

$a, b$ Within a column, means without a common superscript differ at $P<0.05$.

experiments, each repeated on five separate days (Table 1). The experiments were: (I) sample at 0700 and $0900 \mathrm{~h}$, feed at $0900 \mathrm{~h}$; (II) sample and feed at $0700 \mathrm{~h}$; and (III) a repeat of experiment I. Adaptation periods were $7 \mathrm{~d}$ for I, $5 \mathrm{~d}$ for II and $3 \mathrm{~d}$ for III. When the animals were sampled at 0700 and $0900 \mathrm{~h}$ and fed at $0900 \mathrm{~h}$, isotrichid numbers were significantly higher $(P<0.05)$ at $0900 \mathrm{~h}$ in three of the four animals in experiment I and two of the four animals in experiment III. Isotrichid numbers increased significantly $(P<0.05)$ at $0700 \mathrm{~h}$ in these animals between experiments I and II; however, the decreases at $0700 \mathrm{~h}$ between experiments II and III were not significant. These data would substantiate the observation that isotrichid numbers increase before feeding and although there is considerable between-day and between-animal variation, this increase occurs without any previous handling or stimulation of the animals.

\section{Feeding level}

The effect of feed level on numbers of Isotrichidae was investigated using four sheep, each fed a different level of feed one day a week, i.e. $50,100,150$ and $200 \%$ of the amount of feed given on all other days $(800 \mathrm{~g})$. The data from all animals were combined to produce the graphs shown in Fig. 4. The sheep were fed the different amounts at $0900 \mathrm{~h}$. Numbers of isotrichids appeared to be inversely related to feed level, i.e. more sequestration apparently occurred with higher feed intakes. Although the mean differences appeared to be large, only the differences at $3 \mathrm{~h}$ after feeding $(1200 \mathrm{~h})$ were significant. Isotrichid numbers at the $50 \%$ feed level were greater than all 


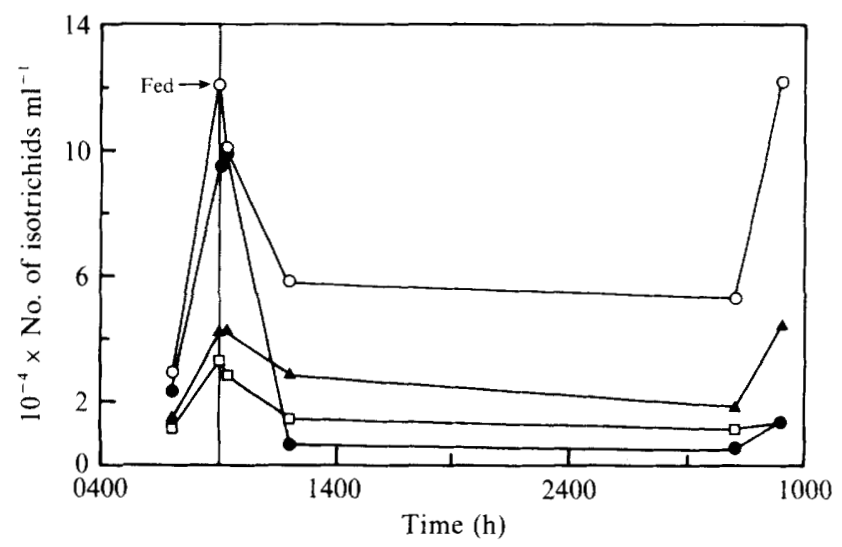

Fig. 4. Influence of feed level on numbers of isotrichids. Normal feed level $(100 \%)$ was 800 g. $\bigcirc, 50 \%$ of normal feed level; $\Delta, 100 \% ; \square, 150 \% ; 0,200 \%$. Values are means of results from four sheep.

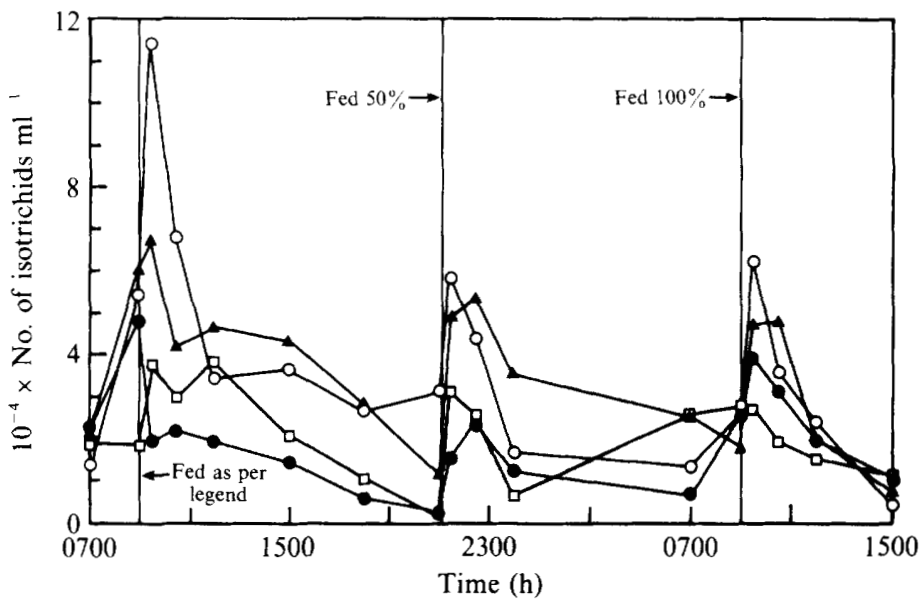

Fig. 5. Effect of feed level on changes in numbers of isotrichids resulting from feeding 12 and $24 \mathrm{~h}$ after normal feeding time. Different amounts were fed at $0900 \mathrm{~h}$ on day $1,50 \%$ of the normal daily ration was fed at $12 \mathrm{~h}$ and $100 \%(800 \mathrm{~g})$ was fed at $24 \mathrm{~h}$. Feed level and sheep no. were : $\mathrm{O}, 25 \%(\operatorname{sheep~} 2) ; \boldsymbol{\Delta}, 50 \%$ (sheep 3); $\square, 100 \%$ (sheep 4);, $125 \%$ (sheep 6).

others at that time, and numbers at the 100 and $150 \%$ feed levels were greater than at $200 \%$ $(P<0.05)$. Variation both within and between animals was large. When the numbers of isotrichids at 1200 , and at 0700 and $0900 \mathrm{~h}$ on day 2 , were all combined, the total at the $50 \%$ feed level was significantly higher than all other levels $(P<0.05)$. The total at the $100 \%$ feed level was higher $(P<0.05)$ than at 150 and $200 \%$, which were not different.

In a related experiment (data not shown), $20 \mathrm{~g}$ corn starch, $40 \mathrm{~g}$ sucrose and $20 \mathrm{~g}$ casein hydrolysate in $200 \mathrm{ml}$ water were added to the rumen $30 \mathrm{~min}$ after feeding. Isotrichid numbers decreased to a greater extent with the addition of the soluble substrates.

To evaluate further the effect of feed level on the chemotactic response, the four sheep were each fed a different amount of diet, i.e. $25,50,100$ or $125 \%$ of normal $(800 \mathrm{~g})$. After $12 \mathrm{~h}$ all animals were fed $50 \%$ of the normal amount and $12 \mathrm{~h}$ later were offered their normal ration. The results of this experiment (Fig. 5) indicate that the isotrichids in sheep at all feed levels showed chemotaxis to incoming feed at both 12 and $24 \mathrm{~h}$. However, the magnitude of response appeared to be inversely related to initial feed level, i.e. larger increases with lower feed intake. 


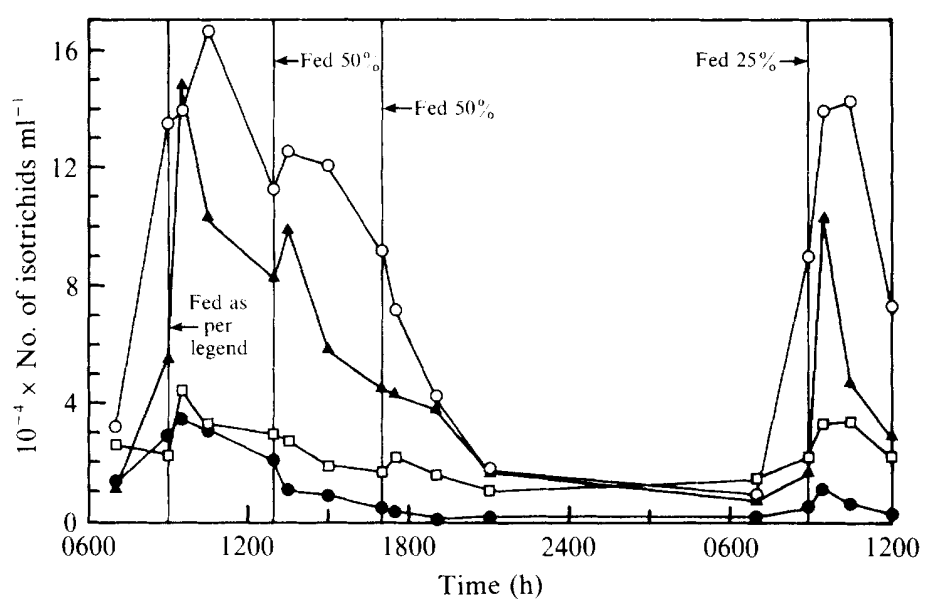

Fig. 6. Effect of feed level on changes in numbers of isotrichids resulting from feeding 4,8 and $24 \mathrm{~h}$ after the normal feeding time. Different amounts were fed at $0900 \mathrm{~h}$ on day $1,50 \%$ of the normal daily ration of $800 \mathrm{~g}$ was fed at 4 and $8 \mathrm{~h}$ and $25 \%$ of the daily ration was fed at $24 \mathrm{~h}$. Feed level and sheep no. were: $\bigcirc, 25 \%$ (sheep 2); $\boldsymbol{\Delta}, 50 \%$ (sheep 3 ); $\square, 100 \%$ (sheep 4 );, $125 \%$ (sheep 6 ).

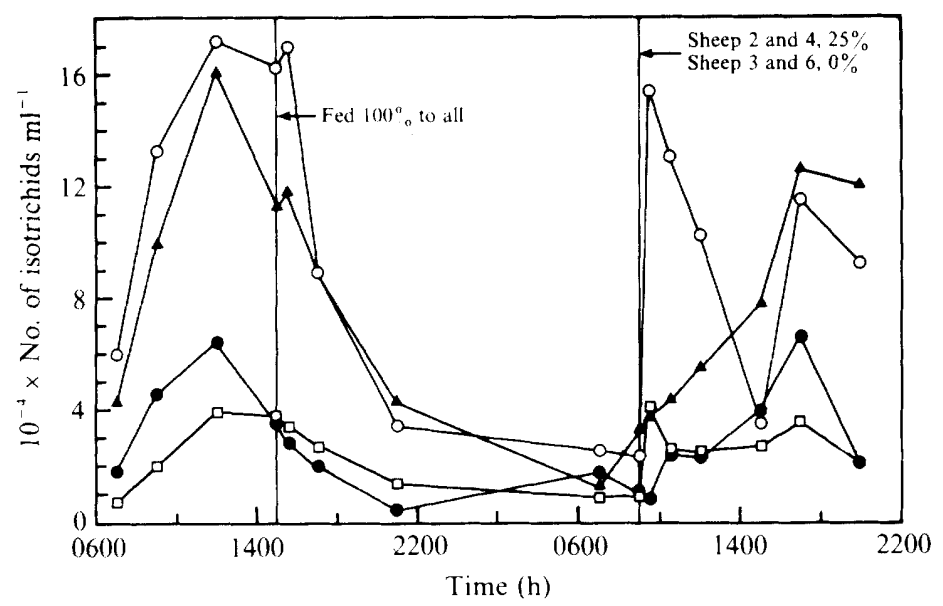

Fig. 7. Effect of delayed feeding on changes in numbers of isotrichids in response to subsequent feedings. Sheep 2 and 4 were fed $25 \%$ of the $800 \mathrm{~g}$ daily ration at the normal feeding time of $0900 \mathrm{~h}$ on day 2 . Sheep 3 and 6 were not fed. $\bigcirc$, Sheep $2 ; \boldsymbol{\Delta}$, sheep $3 ; \square$, sheep 4 ; 0 , sheep 6 .

A somewhat similar experiment was done in which the four different amounts of feed were given at $0900 \mathrm{~h}$, but $50 \%$ of the diet was then fed at 4 and $8 \mathrm{~h}$. After $24 \mathrm{~h}$, only $25 \%$ of the diet was fed to all animals. A small chemotactic response to feeding was observed at $4 \mathrm{~h}$ in the two animals initially fed the two lower feed levels (Fig. 6). No further response was elicited after an additional $4 \mathrm{~h}$ when most of the isotrichids appeared to sequester. A chemotactic response to feeding $25 \%$ of the diet was observed in all animals at $24 \mathrm{~h}$. The increase in numbers was greater in those animals initially fed the lower amounts of feed. Some increase in the numbers of isotrichids was observed before feeding in the animal initially fed at the $25 \%$ level.

If feeding was delayed for $6 \mathrm{~h}$, most of the isotrichids had apparently migrated into the rumen contents and little if any chemotaxis was observed (Fig. 7). A chemotactic response was noted $18 \mathrm{~h}$ later in sheep 2 and 4 when fed $25 \%$ of their normal diet. Sheep 3 and 6 were not fed $18 \mathrm{~h}$ later; however, the isotrichids began to migrate into the rumen contents, reaching a peak at $26 \mathrm{~h}$ after the previous feeding. 


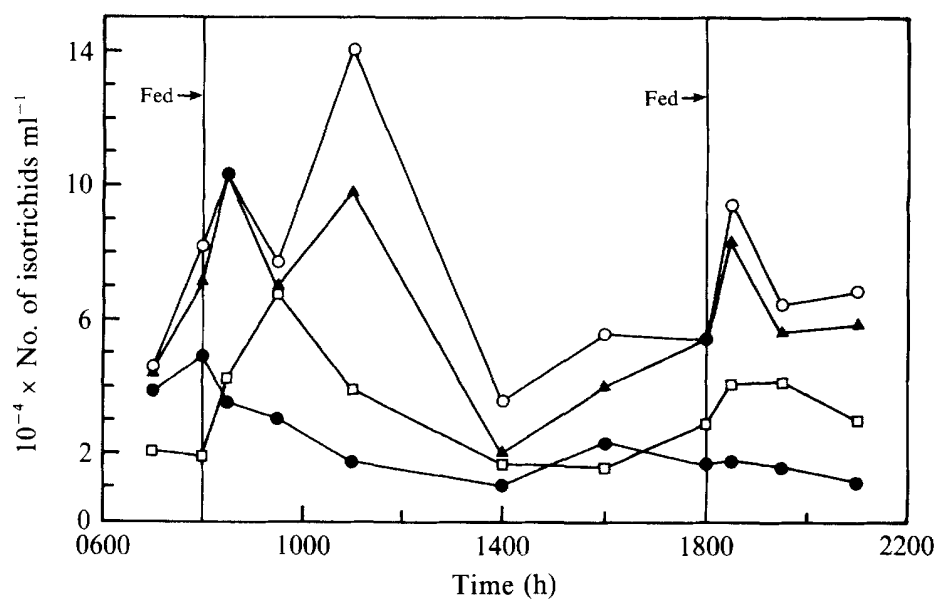

Fig. 8. Changes in numbers of isotrichids in relation to feeding $50 \%$ of the $800 \mathrm{~g}$ daily ration at 0800 and 1800 h. $O$, Sheep $2 ; \boldsymbol{\Delta}$, sheep $3 ; \square$, sheep $4 ; \boldsymbol{O}$, sheep 6.

\section{Frequency of feeding}

At this point, it was unclear as to whether the isotrichids which migrated into the rumen contents in response to additional feeding at $12 \mathrm{~h}$ were the same organisms which had sequestered at the normal feeding time. Also, would these cells sequester and exhibit chemotaxis after an additional $12 \mathrm{~h}$, at the next normal feeding time? In other words, did the isotrichids migrate on the basis of time or level of feed intake? Some of the present data suggest that feed level or intracellular concentration of storage polysaccharide might be the controlling factor. To investigate this question, the animals' feeding schedule was changed so that they received $50 \%$ of the normal $800 \mathrm{~g}$ diet at 0800 and $1800 \mathrm{~h}$. Diurnal concentration curves for sheep 2, 3, 4 and 6 (Fig. 8) showed that the rate of sequestration of the isotrichids appeared to be somewhat slower after the $0800 \mathrm{~h}$ feeding than when all of the daily ration was fed at one time. The increase in numbers after feeding at $1800 \mathrm{~h}$ was markedly lower than after the morning feeding. Similar data were obtained in a replicate experiment.

\section{Effect of removing the rumen contents}

Fig. 9 shows the normal diurnal cycle for isotrichids in sheep 3 (day 1). On day 2 , only $35 \%$ of the ration was fed at $0800 \mathrm{~h}$ and $800 \mathrm{ml}$ of rumen contents were removed at $0830 \mathrm{~h}$. After removal, an equal volume of warm buffer was added and the animal was fed $35 \%$ of its daily ration. The number of isotrichids in the rumen contents removed was $11.4 \times 10^{4} \mathrm{ml}^{-1}$. The number of isotrichids which migrated into the rumen at $1700 \mathrm{~h}$ was markedly lower, and only this lower population of isotrichids was observed the next morning at $0830 \mathrm{~h}$. These data suggest that the same isotrichids migrate into the rumen at both 0800 and $1700 \mathrm{~h}$. Similar experiments were done with sheep 2 and 4 (data not shown) except the first day or normal diurnal cycle was not measured. The volume of rumen contents removed and the number of isotrichids were $1200 \mathrm{ml}, 12 \cdot 1 \times 10^{4} \mathrm{ml}^{-1}$ and $1800 \mathrm{ml}, 7 \cdot 0 \times 10^{4} \mathrm{ml}^{-1}$ for sheep 2 and 4 , respectively. Results in both sheep were almost identical to the previous experiment.

For comparison, an experiment was done where rumen contents were removed $6 \mathrm{~h}$ after feeding, when the isotrichids were presumably sequestered (Fig. 10). Removal of $1900 \mathrm{ml}$ of rumen contents at $1400 \mathrm{~h}$ had little effect on the concentration of isotrichids at $1700 \mathrm{~h}$ or $0830 \mathrm{~h}$ the next morning. The first $1800 \mathrm{ml}$ of rumen contents removed contained $2.0 \times 10^{4}$ isotrichids $\mathrm{ml}^{-1}$. The last $100 \mathrm{ml}$ removed with the plastic tube contained $13.7 \times 10^{4}$ isotrichids $\mathrm{ml}^{-1}$, suggesting some sequestration in the ventral part of the rumen. The total number of isotrichids removed in this experiment was $5.0 \times 10^{7}$. This compares to $9 \cdot 1 \times 10^{7}, 14.5 \times 10^{7}$ and $12.6 \times 10^{7}$ 


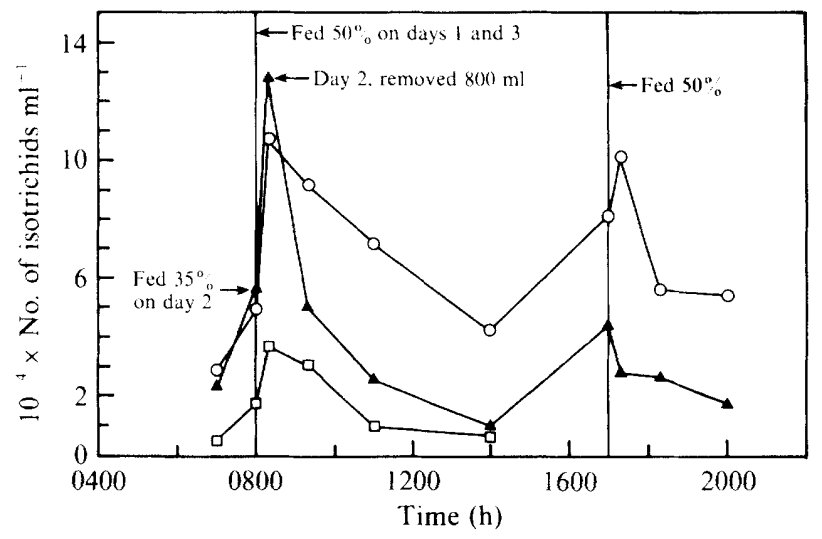

Fig. 9. Effect of removing rumen contents $30 \mathrm{~min}$ after feeding on subsequent numbers of isotrichids (sheep 3). The total daily ration was $800 \mathrm{~g}$. On days 1 and 3,50\% of the daily ration was fed at 0800 and $1700 \mathrm{~h}$. On day $2,35 \%$ of the ration was fed at $0800 \mathrm{~h} ; 800 \mathrm{ml}$ of rumen contents were removed at $0830 \mathrm{~h}$ and replaced by the same volume of anaerobic buffer; $35 \%$ of the ration was then fed. $O$, Day $1 ; \boldsymbol{\Delta}$, day $2 ; \square$, day 3 .

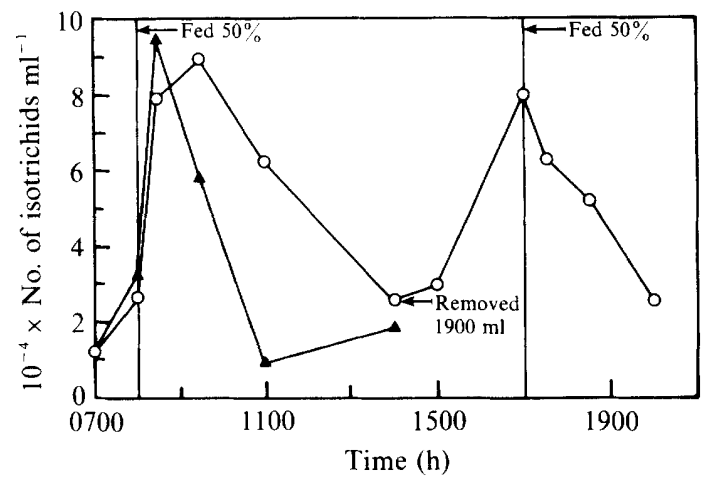

Fig. 10. Effect of removing rumen contents $6 \mathrm{~h}$ after feeding on subsequent numbers of isotrichids (sheep 3). The total daily ration was $800 \mathrm{~g}$. On day $1,1900 \mathrm{ml}$ of rumen contents were removed at $1400 \mathrm{~h}$ and replaced by the same volume of anaerobic buffer. $O$, Day $1 ; \boldsymbol{\Lambda}$, day 2 .

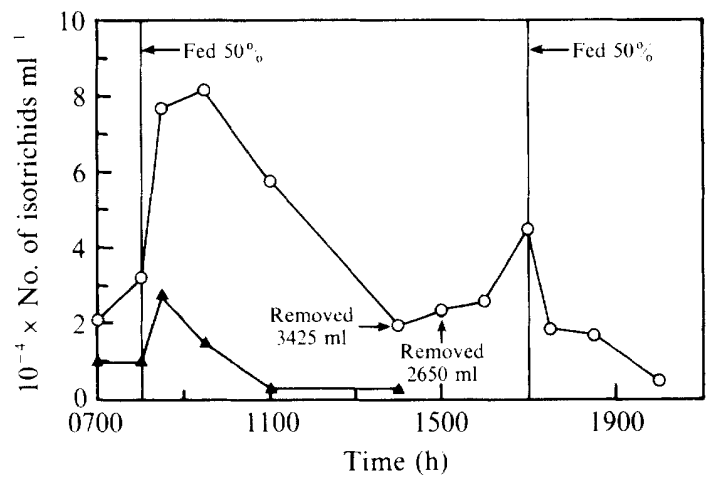

Fig. 11. Effect of removing rumen contents 6 and $7 \mathrm{~h}$ after feeding on subsequent numbers of isotrichids (sheep 3). The total daily ration was $800 \mathrm{~g}$. On day $1,3425 \mathrm{ml}$ of rumen contents were removed at $1400 \mathrm{~h}$ and replaced with anaerobic buffer. At $1500 \mathrm{~h}, 2650 \mathrm{ml}$ rumen contents were removed and replaced with anaerobic buffer. $\mathrm{O}$, Day $1 ; \boldsymbol{\Lambda}$, day 2 . 
total isotrichids removed in the previous experiments, where isotrichid numbers were markedly reduced at $1700 \mathrm{~h}$ and $0830 \mathrm{~h}$ the next day.

Using sheep 3 again, the above experiment was repeated, except in addition to removal of the rumen contents and replacement with buffer at $6 \mathrm{~h}$ after feeding, contents were again removed $7 \mathrm{~h}$ after feeding (Fig. 11). It appears that many of the sequestered isotrichids were removed by this procedure. At $6 \mathrm{~h}$ the number of isotrichids was $1.7 \times 10^{4} \mathrm{ml}^{-1}$ and at $7 \mathrm{~h}, 3.4 \times 10^{4} \mathrm{ml}^{-1}$. The total number of isotrichids removed was $14.8 \times 10^{7}$, which is comparable to the numbers in those experiments where rumen contents were removed 30 min after feeding. Thus, enough isotrichids were removed to affect markedly the numbers available to migrate in response to incoming nutrients at $1700 \mathrm{~h}$ or the next day at $0800 \mathrm{~h}$.

\section{DISCUSSION}

The results obtained in this study clearly indicate that the number of isotrichids in rumen contents is variable and influenced by time of sampling, feed level and frequency of feeding. In an animal fed once daily, numbers can remain about the same or more than double in the $3 \mathrm{~h}$ before feeding (Figs 1 and 3). The chemotactic response to feeding varies with feed level as does the number of isotrichids after feeding (Figs 5,6 and 8). In general, the maximum number of isotrichids, which occurs at or just after feeding, appears to be an equilibrium between migrating and sequestering isotrichids. If one samples rumen contents more than $2-3 \mathrm{~h}$ after feeding, most of the isotrichids will probably be sequestered (Figs 1, 3 and 4).

Data presented in Figs 2 and 7 suggest that in animals fed once daily, the number of isotrichids in the rumen contents of an unfed animal approximately $3 \mathrm{~h}$ after the normal feeding time would probably be the best estimate available of the total number of isotrichids. In most cases isotrichid numbers begin to increase just before or at the normal feeding time and continue to increase for 3-4 h. At that time, numbers begin to decrease whether the animal is fed or not. Presumably the decrease in isotrichid concentration reflects a lack of energy for maintenance of the protozoan cell (Potter \& Dehority, 1973). Since there is apparently little or no increase in isotrichid numbers in response to incoming feed, it might then be assumed that few, if any, of the isotrichids are still sequestered.

The amount of polysaccharide stored in the isotrichid cell is probably a function of feeding level, and may control migration of the isotrichids into the rumen. Essentially, it is proposed that the isotrichids begin to utilize stored polysaccharide shortly after they sequester. Approximately 10-12 h later, depending on previous feed intake, the level of storage polysaccharide has decreased below the chemotactic threshold level, i.e. that point at which the isotrichids will migrate in response to soluble sugars. If the animal receives no nutrients at that time, storage polysaccharides are further utilized until they reach a specific minimum level about $20-22 \mathrm{~h}$ after feeding. At this level of storage polysaccharide, the isotrichids will begin to migrate into the rumen. This latter migration might he termed a depletion response as compared to the chemotactic response discussed above.

Abe et al. (1981), based on visual observations, proposed that the isotrichids sequestered on the wall of the reticulum. They observed a thick protozoal mass after overnight starvation, which could readily be dislodged or dispersed by vigorous agitation of the reticulum wall. We have observed in the present study and previously that when samples of rumen contents are removed from sheep about $30 \mathrm{~min}$ after feeding, and placed in a large beaker, white masses visible to the naked eye form on the top, bottom and at various layers in the contents. Microscopic observation of this material revealed that it is composed primarily of isotrichids, similar to the protozoal mass described by Abe et al. (1981).

Sequestration may occur as a result of the densely filled isotrichids settling to the bottom of the rumen, and not solely by attachment on the reticulum wall. The data shown in Fig. 10 indicate that a large number of isotrichids occur in the bottom of the rumen. In another experiment (Fig. 11), removal of contents, addition of buffer and removal of contents $1 \mathrm{~h}$ later markedly reduced 
the number of isotrichids. This would be considered a rather mild treatment and since no soluble sugars were added, chemotaxis should not be a factor. Thus, in addition to possible sequestration on the wall of the reticulum the isotrichids appear to settle in the ventral rumen. If they adhere to the wall, the association seems to be quite loose and readily disrupted.

This research was supported by State and Federal funds appropriated to the Ohio Agricultural Research and Development Center, The Ohio State University. Manuscript no. 98-88.

\section{REFERENCES}

Abe, M., IRIKı, T., Tobe, N. \& ShIBUI, H. (1981). Sequestration of holotrich protozoa in the reticulorumen of cattle. Applied and Environmental Microbiology 41, 758-765.

Bryant, M. P. \& Burkey, L. A. (1953). Cultural methods and some characteristics of some of the more numerous groups of bacteria in the bovine rumen. Journal of Dairy Science 36, 205-217.

Clarke, R. T. J. (1965). Diurnal variation in the numbers of rumen ciliate protozoa in cattle. New Zealand Journal of Agricultural Research 8, 1-9.

DEHORITY, B. A. (1970). Occurrence of the ciliate protozoa Butschlia parva Schuberg in the rumen of the ovine. Applied Microbiology 19, 179-181.

DEHORITY, B. A. (1984). Evaluation of subsampling and fixation procedures used for counting rumen protozoa. Applied and Environmental Microbiology 48, 182-185.

Dehority, B. A. \& Mattos, W. R. S. (1978). Diurnal changes and effect of ration on concentrations of the rumen ciliate Charon ventriculi. Applied and Environmental Microbiology 36, 953-958.

Honigberg, B. M., Balamuth, W., Bovee, E. C., Corliss, J. O., Gojdics, M., Hall, R. P., Kudo, R. R., LeVINe, N. D., LOEBliCH, A. R., JR, WeISER, J. \& WENRICH, D. H. (1964). A revised classification of the phylum protozoa. Journal of Protozoology 11, 720.

Levine, N. D., Corliss, J. O., CoX, F. E. G., Deroux, G., Grain, J., Honigberg, B. M., Leedale, G. F., Loeblich, A. R., III, LOM, J., LYNN, D., MERINfeld, E. G., Page, F. C., Poljansky, G., Sprague, V., Vavra, J. \& Wallace, F. G. (1980). A newly revised classification of the protozoa. Journal of Protozoology 27, 37-58.
Michalowski, T. (1975). Effect of different diets on the diurnal concentrations of ciliate protozoa in the rumen of water buffalo. Journal of Agricultural Science 85, 145-150.

Michalowski, T. (1977). Diurnal changes in concentration of rumen ciliates and in occurrence of dividing forms in water buffalo (Bubalus bubalus) fed once daily. Applied and Environmental Microbiology 33, 802-804.

MurPhy, M. R., Drone, P. E., JR \& WoOdFord, S. T. (1985). Factors stimulating migration of holotrich protozoa into the rumen. Applied and Environmental Microbiology 49, 1329-1331.

ORPIN, C. G. \& LeTCHER, A. J. (1978). Some factors controlling the attachment of the rumen holotrich protozoa Isotricha intestinalis and I. prostoma to plant particles in vitro. Journal of General Microbiology 106, 33-40.

Potter, E. L. \& Dehority, B. A. (1973). Effects of changes in feed level, starvation and level of feed after starvation upon the concentration of rumen protozoa in the ovine. Applied Microbiology 26, 692698.

Purser, D. B. (1961). A diurnal cycle for holotrich protozoa of the rumen. Nature, London 190, 831-832.

Purser, D. B. \& MoIR, R. J. (1959). Ruminal flora studies in the sheep. IX. The effect of $\mathrm{pH}$ on the ciliate population of the rumen in vivo. Australian Journal of Agricultural Research 10, 555-564.

WARner, A. C. I. (1966). Diurnal changes in the concentrations of microorganisms in the rumens of sheep fed limited diets once daily. Journal of General Microbiology 45, 213-235. 